\title{
Seroprevalence studies on animal chlamydiosis amongst ruminants in five states of India
}

\author{
R. Chahota, S. Gupta, B. Bhardwaj, P. Malik, S. Verma and M. Sharma
}

\begin{abstract}
Department of Veterinary Microbiology, DGCN College of Veterinary and Animal Sciences, Palampur, Himachal Pradesh, India. Corresponding author: R. Chahota, e-mail: rchahota@yahoo.com, SG: shilpi5.biotech@gmail.com, BB: lucky000051@gmail.com, PM: priyanka7malik@gmail.com, SV: sverma8@yahoo.co.uk, MS: mandeepsharma289@hotmail.com Received: 16-09-2014, Revised: 08-12-2014, Accepted: 12-12-2014, Published online: 24-01-2015
\end{abstract}

doi: 10.14202/vetworld.2015.72-75. How to cite this article: Chahota R, Gupta S, Bhardwaj B, Malik P, Verma S, Sharma M (2015) Seroprevalence studies on animal chlamydiosis amongst ruminants in five states of India, Veterinary World, 8(1): 72-75.

\begin{abstract}
Background and Aim: Animal chlamydiosis, caused by different chlamydial species, is characterized by clinical or subclinical disease manifestations in cattle, buffalo, ovine, caprine and wild animal species. Animal chlamydiosis often remains underdiagnosed or undiagnosed, and its status in many parts of India is still unknown. Hence, the present study was conducted to determine the seroprevalence of animal chlamydiosis amongst ruminant livestock species of five states of India.
\end{abstract}

Materials and Methods: Totally, 2127 randomly selected serum samples collected from ruminant livestock species viz. cattle ( $n=430)$, buffaloes ( $n=429)$, sheep (906) and goats $(n=362)$, were tested by agar gel precipitation test for chlamydiosis between 2002 and 2011. Precipitating antigen was prepared from locally isolated strain of Chlamydia psittaci after treatment with sodium deoxycholate.

Results: The chlamydial seroprevalence detected amongst ruminants in five states of India was: Himachal Pradesh: Cattle-10.90\%, sheep-10.60\% and goats- 22.46\%; Punjab: Cattle-1.45\%; Andhra Pradesh: Cattle-2.80\%, buffaloes-0.93\%, sheep-8.90\% and goats-9.46\%; Maharashtra: goats-8.33\%; Jammu and Kashmir: sheep-12.50\%. The mean seroprevalence values of each animal species are: Cattle-4.65\%, buffaloes-0.93\%, sheep-9.82\% and goats-19.33\%.

Conclusion: The results indicate the endemic nature of animal chlamydiosis across five states in India. Hence, it requires further extensive studies in other parts of India also using chlamydial species-specific diagnostics to ascertain overall countrywide prevalence of the disease. The zoonotic nature of the chlamydiae of ruminant origin further adds significance to such prevalence studies.

Keywords: agar gel precipitation test, chlamydiosis, ruminants, seroprevalence

\section{I ntroduction}

Chlamydiae are obligate intracellular bacterial pathogens, responsible for diverse disease conditions in animals, birds and humans [1-3]. Chlamydiae undergo a unique biphasic developmental cycle characterized by two morphologically distinct forms called the elementary body (EB) and the reticulate body. Chlamydiae, a genetically diverse group of organisms belonging to order Chlamydiales, family Chlamydiaceae were grouped into two genera, Chlamydia and Chlamydophila, containing nine species [4]. But recently, a single genus classification (Chlamydia) with 11 species has been adopted by International Committee on Systematics of Prokaryotes [5] and is currently being followed [2-6]. Animal chlamydial infections are caused by different chlamydial species of the genus Chlamydia. Amongst ruminants, Chlamydia abortus, Chlamydia pecorum and Chlamydia psittaci cause clinical infections [7-9]. C. abortus causes abortion, infertility and

Copyright: The authors. This article is an open access article licensed under the terms of the Creative Commons Attributin License (http:// creative commons.org/licenses/by/2.0) which permits unrestricted use, distribution and reproduction in any medium, provided the work is properly cited. weak offspring in sheep, goats, cows and buffaloes, whereas, C. pecorum is associated with chronic conditions such as pneumonia, polyarthritis, conjunctivitis, enteritis, encephalomyelitis, metritis and mastitis amongst ruminants. C. psittaci mainly causes "avian chlamydiosis" amongst 471 reported avian species [10] but can also infect mammalian species including ruminants [9]. Chlamydiae are also accountable for direct zoonosis (animals to humans) without the involvement of any intermediate host and some species like C. psittaci, C. abortus, Chlamydia caviae and Chlamydia felis are confirmed zoonotic pathogens [11,12].

Chlamydial diseases amongst ruminants are known in India since long time $[13,14]$ but as the result of using improved diagnostic techniques in recent years, chlamydiosis has been recognized as one of the important health problems in livestock [15-17]. Recent serological surveys carried out in many countries to know the status of chlamydiosis in native livestock species using different screening tests have revealed the prevalence of this disease to variable extent in both diseased and normal animals [17-19]. In India, the prevalence of animal chlamydiosis is well studied in only few areas but little is known about 
its status in other states due to the difficulty associated with the handling of this fastidious intracellular pathogen.

Hence, the present study was undertaken to investigate the seroprevalence of animal chlamydiosis in five states of India.

\section{Materials and Methods}

\section{Ethical approval}

Prior consent of the owners of the animals was taken before collection of blood samples for serum extraction. Proper ethical considerations related to animal handling were observed and ensuring not to cause any injury during sampling. The other institutes that submitted the serum samples for diagnosis of the chlamydiosis addressed the animal ethics issues according the local regulations.

\section{Samples}

The study was conducted during the period of 2002-2011 using 2127 serum samples collected randomly or submitted to the Department of Veterinary Microbiology for chlamydial diagnosis from populations of ruminant livestock species from five different states such as Himachal Pradesh, Punjab, Jammu and Kashmir, Andhra Pradesh and Maharashtra. The detail of sample collection is shown in Table-1.

\section{Chlamydial group specific antigen preparation}

Chlamydial group specific antigen was prepared from locally isolated C. psittaci strain from the placenta of an aborted sheep that was multiplied in McCoy cell line. The cells were maintained in Eagle's minimum essential medium (Gibco) containing 5\% fetal bovine serum and $10 \mu \mathrm{g} / \mathrm{ml}$ of gentamicin and $1 \mu \mathrm{g} / \mathrm{ml}$ of cycloheximide and incubated at $37^{\circ} \mathrm{C}$ in $5 \% \mathrm{CO}_{2}$. The EBs were harvested 3-4 days after inoculation and were partially purified. AGPT antigen was prepared by treating these EBs with sodium deoxycholate as reported earlier [20].

\section{Chlamydia specific positive serum}

Positive serum used in test proper was raised in rabbit using above-mentioned strain of $C$. psittaci as described earlier [21]. Briefly, $100 \mu \mathrm{g}$ of EB protein was treated with $1 \%$ Triton X-100 in $1 \mathrm{ml}$ of phosphate-buffered saline at $37^{\circ} \mathrm{C}$ for $1 \mathrm{~h}$ and sonicated. The EBs were emulsified with an equal volume of Freund's complete adjuvant (Sigma) and given intramuscularly. After 3 weeks, a series of five intravenous injections of treated antigen were given at 3 days

Table 1: Details of the samples collected from small and large ruminants

\begin{tabular}{lccccc}
\hline Name of the state Cattle Buffaloes Sheep & Goats & Total \\
\hline Himachal Pradesh & 110 & - & 415 & 276 & 801 \\
Punjab & 69 & - & - & - & 69 \\
Andhra Pradesh & 251 & 429 & 467 & 74 & 1221 \\
Maharashtra & - & - & - & 12 & 12 \\
Jammu and Kashmir & - & - & 24 & - & 24 \\
Total & 430 & 429 & 906 & 362 & 2127 \\
\hline
\end{tabular}

intervals for the first four injections and 7 days for the fifth, in progressively increasing doses $(10,10,15,20$, and $50 \mu \mathrm{g}$ of protein). Rabbits were bled 1 week after the last injection. Hyperimmune serum was suitably diluted for using in test proper.

\section{Agar gel precipitation test (AGPT)}

The AGPT test was performed as described earlier [22] with minor modifications using $1 \%$ agar in normal saline solution. Briefly $4-5 \mathrm{ml}$ of molten agar was pipetted onto microscope slides. Wells of $4.0 \mathrm{~mm}$ diameter were cut into the hardened agar at 3-4 $\mathrm{mm}$ distance. The slides were incubated at $4^{\circ} \mathrm{C}$ in a humidified chamber and appearance of whitish lines of the precipitation reaction in the test and control samples were recorded after 16-24 $\mathrm{h}$. The antigen-antibody reaction in the form of clear precipitation line was observed in chlamydia positive cases. Negative and positive serum controls were also kept along with each test.

\section{Statistical analysis}

The hypothesis that the seroprevalence of chlamydiosis in animal populations of different states is same was tested using $\chi^{2}$ test function in Microsoft Excel software at $5 \%(0.05<\mathrm{p})$ significance level and results of observed prevalence (experimental hypothesis) were analyzed.

\section{Results and Discussion}

Chlamydial infections have been reported from different livestock species globally $[2,23,24]$. In India, chlamydiae are reported to cause abortions, infertility, conjunctivitis, pneumonitis, enteritis and encephalomyelitis amongst cattle, sheep, goats and equines [12-16]. Though direct evidence of the infectious agent is the ultimate diagnosis, sero-assays are more suitable for screening large numbers of population samples especially when samples are to be analyzed in another laboratory. Serodetection of circulating antibody is a convenient method for detecting infectious diseases. Seronegative results would indicate no previous contact with chlamydiae, whereas, seropositive test indicates an active infection in test animal or being a potential carrier of the disease. Different serological tests for the detection of chlamydial infections are reported such as microimmunoflorescence, enzyme-linked immunosorbent assay, AGPT, complement fixation test and indirect hemagglutination assay. These tests differ in their sensitivities and specificities, depending primarily on the antigen preparation, and all the applied serological methods can be widely used in laboratories as diagnostic methods for establishing infections amongst ruminants with Chlamydia spp. Though, AGPT is less sensitive but does not require any specialized infrastructure and can easily be performed under in house conditions. AGPT is reported to detect chlamydial complement fixation antibody titer of more than 8, which is considered advantageous in ruling out weak reactors in case of field studies [22]. 
Table 2: Seroprevalence of chlamydial infections amongst ruminants

\begin{tabular}{lccccc}
\hline Name of the state & Cattle (\%) & Buffaloes (\%) & Sheep (\%) & Goats (\%) & Total (\%) \\
\hline Himachal Pradesh & $12 / 110(10.90)$ & - & $44 / 415(10.60)$ & $62 / 276(22.46)$ & $118 / 801(14.73)$ \\
Punjab & $1 / 69(1.45)$ & - & - & - & $1 / 69(1.45)$ \\
Andhra Pradesh & $7 / 251(2.80)$ & $4 / 429(0.93)$ & $42 / 467(8.90)$ & $7 / 74(9.46)$ & $60 / 1221(4.91)$ \\
Maharashtra & - & - & - & $1 / 12(8.33)$ & $1 / 12(8.33)$ \\
Jammu and Kashmir & - & - & $3 / 24(12.5)$ & - & $3 / 24(12.5)$ \\
Total & $20 / 430(4.65)$ & $4 / 429(0.93)$ & $89 / 906(9.82)$ & $70 / 362(19.33)$ & $183 / 2127(8.60)$ \\
\hline
\end{tabular}

Note: Positive percentages are shown in the parenthesis

Analysis of disease-related data from five states revealed that seroprevalence was highest, i.e. 19.33\% amongst goats. However, seroprevalence of chlamydiosis amongst goats of different states of India showed variations from $8.33 \%$ in Maharashtra to 22.46\% in Himachal Pradesh, and the detail is shown in Table-2. The low positive percentage in Maharashtra may be due to small sample size. Amongst sheep population, we detected a mean prevalence of $9.82 \%$, ranging from $8.9 \%$ in Andhra Pradesh to $10.6 \%$ in Himachal Pradesh. Studies on limited samples and area in India by Mahapatra et al. [25] using AGPT for chlamydiosis, recorded $28.0 \%$ and $34.0 \%$ seropositivity for sheep and goat, respectively. Similarly, Joshi et al. [26] also reported seropositivity of $29.90 \%$ and $43.29 \%$ in sheep and goats, respectively. In cattle and buffaloes, overall $4.65 \%$ and $0.93 \%$ samples were found seropositive, respectively in our study. We tested 429 samples of buffaloes from Andhra Pradesh only; however, it requires further studies of buffalo samples from other parts of India also. In one of our previous studies on buffalo serum using AGPT, total 8.70\% samples were found positive from Himachal Pradesh [14]. In this study, no significant statistical difference was found in the seroprevalence of chlamydiosis amongst ruminants of five different states of India. This may be due to the small size of the representative samples from each state. Thus, a more exhaustive epidemiological study is required to know the actual chlamydial prevalence in different states. Though, the present investigation underlines the importance of the animal chlamydiosis on the health of livestock in India. It is observed that seropositivity for chlamydiosis varies frequently amongst animals because of several influencing factors including the degree of exposure to infection, feeding habitats, virulence of chlamydial strains and possibly innate immunity amongst animal species. But for population-based studies to determine the prevalence of any disease this approach is indispensable. Therefore, recently numerous serologic surveys on the prevalence of chlamydiosis amongst ruminants have been carried out in other countries to ascertain the effect of chlamydiosis on animal health and production [17,18,27-29]. Thus, in India, extensive epidemiological studies are required to be undertaken including more livestock populations of different geographical locations of the country for better understanding of animal chlamydiosis.

\section{Conclusion}

The results of the present investigation indicated that chlamydial infections are endemic amongst ruminants in studied areas of five states of India, which may represents one of the causes of abortion, pneumonia, enteritis, arthritis and other clinical manifestations. Therefore, large-scale screening of native livestock species along with characterization of involved indigenous chlamydial strains is urgently required. Thus, integrated strategies are required to be adopted for control and prevention of sporadic chlamydial infection cases or disease outbreaks keeping in view the zoonotic importance also.

\section{Authors' Contributions}

RC was associated with overall planning and execution of the research work. SG, BB and PM carried out laboratory work. SV and MS analyzed the data and drafted and revised the manuscript. All authors read and approved the final manuscript.

\section{Acknowledgments}

The authors are thankful to Department of Biotechnology (DBT), Ministry of Science and Technology, Government of India, New Delhi, for partly funding this study (DBT Grant No GOI-468/40).

\section{Competing I nterests}

The authors declare that they have no competing interests.

\section{References}

1. Stephens, R.S. (1999) Chlamydia: Intracellular Biology, Pathology, and Immunity. American Society for Microbiology, Washington, DC.

2. Horn, M. (2011) Phylum XXIV: Chlamydiae. In: Krieg, N.R., Staley, J.T., Brown, D.R., Hedlund, B.P., Pastor, B.J., Ward, N.L., Ludwig, W. and Whitman, WB, editors. Bergey's Manual of Systematic Bacteriology. Vol. 4. Springer, New York. p843-877.

3. Markey, B. (2011) Chlamydial infection in cattle: The burden of proof? Vet. J., 189(3): 246-247.

4. Everett, K.D.E., Bush, R.M. and Andersen, A.A. (1999) Emended description of the order Chlamydiales, proposal of Parachlamydiaceae fam. nov. and Simkaniaceae fam. nov, each containing one monotypic genus, revised taxonomy of the family Chlamydiaceae including a new genus and five new species, and standards for the identification of organisms. Int. J. Syst. Evol. Microbiol., 49: 415-440.

5. Greub, G. (2010) International committee on systematics of prokaryotes. Subcommittee on the taxonomy of the Chlamydiae: Minutes of the closed meeting, 21 June 2010, 
Hof bei Salzburg, Austria. Int. J. Syst. Evol. Microbiol., 60(11): 2694.

6. Kuo, C.C., Stephens, R.S., Bavoil, P.M. and Kaltenboeck, B. (2011) Genus I. Chlamydia. In: Krieg, N.R., Staley, J.T. and Brow, D.R. editors. Bergey's Manual of Systematic Bacteriology. $2^{\text {nd }}$ ed. Vol. 4. Springer-Verlag, New York, USA. p843-865.

7. Reinhold, P., Sachse, K. and Kaltenboeck, B. (2011) Chlamydiaceae in cattle: Commensals, trigger organisms, or pathogens? Vet. J., 189(3): 257-267.

8. Mohamad, K.Y. and Rodolakis, A. (2010) Recent advances in the under-standing of Chlamydophila pecorum infections, 16 years after it was named as the fourth species of the Chlamydiaceae family. Vet. Res., 41: 27.

9. Knittler, R., Berndt, A., Böcker, S., Dutow, P., Hänel, F., Heuer, D., Kägebein, D., Klos, A., Koch, S., LieblerTenorio, E., Ostermann, C., Reinhold, P., Saluz, H.P., Schöfl, G., Sehnert, P. and Sachse, K. (2014) Chlamydia psittaci: New insights into genomic diversity, clinical pathology, host-pathogen interaction and antibacterial immunity. Int. J. Med. Microbiol., 304(7): 877-93.

10. Chahota, R., Ogawa, H., Mitsuhashi, Y., Ohya, K., Yamaguchi, T. and Fukushi, H. (2006) Genetic diversity and epizootiology of Chlamydophila psittaci prevalent among the captive and feral avian species based on VD2 region of ompA gene. Microbiol. Immunol., 50(9): 663-678.

11. Rodolakis, A. and Mohamad, K.Y. (2010) Zoonotic potential of Chlamydophila. Vet. Microbiol., 140: 382-391.

12. Chahota, R. and Sharma, M. (2014) Chlamydophila infections. In: Garg, S.R. and editor. Zoonoses: Bacterial Diseses. $\mathrm{I}^{\mathrm{st}}$ ed. Daya Publishing House, New Delhi. p245-263.

13. Dhingra, P.N., Agarwal, L.P., Mahajan, V.M. and Adalakha, S.C. (1994) Isolation of chlamydia from pneumonic lungs of buffaloes, cattle and sheep. Zentralbl. Veterinarmed. B., 27B(8): 680-682.

14. Katoch, R.C., Sharma, M., Chahota, R., Dhar, P., Chauhan, B.C. and Singh, C. (2003) Seroprevalence of chlamydial infections among buffaloes of Himachal Pradesh, India. Buffalo Bull., 22(4): 75-77.

15. Katoch, R.C., Chahota, R., Sharma, M. and Nagal, K.B. (2002) Chlamydiosis in livestock of H.P. In: Kapoor, A.C. and editor. Proceedings of International Symposium on Sustainable Agriculture in Hill Areas. $\mathrm{I}^{\text {st }}$ ed. Palampur, India. p225-232.

16. Bhardwaj, B. (2011) M.V.Sc. Thesis. C.S.K. Himachal Pradesh Krishi Vishvavidyalaya, Palampur.

17. Bandyopadhyay, S., Sasmal, D., Biswas, T.K., Samanta, I. and Ghosh, M.K. (2009) Serological evidences of antibodies against Chlamydophila abortus in free-ranging yak (Poephagus grunniens) in Arunachal Pradesh, India. Rev. Sci Tech. OIE, 28: 1051-1055.
18. Chen, Q., Gong, X., Zheng, F., Cao, X., Li, Z. and Zhou, J. (2014) Seroprevalence of Chlamydophila abortus infection in yaks (Bos grunniens) in Qinghai, China. Trop. Anim. Health Prod., 46: 503-507.

19. Osman, K.M., Ali, H.A., ElJakee, J.A. and Galal, H.M. (2012) Chlamydiaceae in riverine buffalo (Bubalus bubalis) and cows (Bos taurus) in Egypt with and without signs of reproductive disease. N. Z. Vet. J., 60(4): 228-233.

20. Evans, R.T. and Taylor-Robinson, D. (1982) Development and evaluation of an enzyme-linked immunosorbent assay (ELISA), using chlamydial group antigen, to detect antibodies to Chlamydia trachomatis. J. Clin. Pathol., 35: 1122-1128.

21. Fukushi, H. and Katsuya H. (1988) Immunochemical diversity of the major outer membrane protein of avian and mammalian Chlamydia psittaci. J. Clin. Microbiol., 26(4): 675-680.

22. Barron, A.L., Caste, P.G., Paul, B. and Page, L.A. (1972) Detection of chlamydial antibodies in animal sera by double diffusion in gel. Appl. Microbiol., 23(4): 770-774.

23. OIE. (2011) Enzootic Abortion of ewes (ovine chlamydiosis). In: Manual of Diagnostic Tests and Vaccines for Terrestrial Animals. Chapter 2.3.1. World Organisation for Animal Health, Paris. Available from: http://www.oie. int/fileadmin/Home/eng/Health_standards/tahm/2.07.07_ ENZ_ABOR.pdf

24. Lenzko, H., Moog, U., Henning, K., Lederbach, R., Diller, R., Menge, C., Sachse, K. and Sprague, L.D. (2011) High frequency of chlamydial co-infections in clinically healthy sheep flocks. BMC Vet. Res., 7: 29.

25. Mahapatra, D., Mishra, A. and Misra, P.K. (1987) Chlamydial infections in sheep and goat. Indian. J. Vet. Med., 7(2): 173-174.

26. Joshi, V.B., Chahota, R., Katoch, R.C., Batta, M.K., Nagal, K.B., Sharma, M. and Saini, S.S. (1997) Gel precipitation antibodies to Chlamydia psittaci among livestock, birds and humans. Indian J. Anim. Sci., 67(2): 115-116.

27. Ababneh, H.S., Ababneh, M.M.K., Hananeh, W.M., Alsheyab, F.M., Jawasreh, K.I., Al-Gharaibeh, M.A. and Ababneh, M.M. (2014) Molecular identification of chlamydial cause of abortion in small ruminants in Jordan. Trop. Anim. Health Prod., 46(8): 1407-12.

28. Silva-Zacarias, F.G., Spohr, K.A.H., Lima, B.A.C., Dias, J.A., Muller, E.E., Neto, J.S.F., Turilli, C. and Freitas, J.C. (2009) Prevalence of antibodies against Chlamydophila spp. in herds with bovine abortion of Parana state, Brazil. Pesqui. Vet. Bras., 29: 215-219.

29. Talafha, A.Q., Ababneh, M.M. and Al-Majali, A.M. (2012) Prevalence and risk factors associated with Chlamydophila abortus infection in dairy herds in Jordan. Trop. Anim. Health Prod., 44: 1841-1846. 